\title{
Effects of Anti-Anginal Agents on Cyclical Reductions of Coronary Blood Flow
}

\author{
Yasumi Uchida, M.D., Nobuo Yoshimoto, M.D., \\ and Satoru Murao, M.D.
}

\begin{abstract}
SUMMARY
The effects of coronary vasodilating agents and alpha- and betaadrenergic blocking agents on cyclical reductions of blood flow in the partially constricted coronary artery of anesthetized dogs were examined. Intravenous injections of nitroglycerin $(50 \mu \mathrm{g} / \mathrm{Kg})$, SG $75(150 \mu \mathrm{g} / \mathrm{Kg})$, papaverine $(1 \mathrm{mg} / \mathrm{Kg})$, and nicotinic acid $(10 \mathrm{mg} / \mathrm{Kg})$ eliminated both cyclical reductions of flow and ST elevation (group 1). Nifedipine (10 $\mu \mathrm{g} / \mathrm{Kg})$, verapamil $(500 \mu \mathrm{g} / \mathrm{Kg})$, diltiazem $(500 \mu \mathrm{g} / \mathrm{Kg})$, and propranolol $(500 \mu \mathrm{g} / \mathrm{Kg}$ ) suppressed ST elevation, but they could not eliminate cyclical reductions of flow (group 2). Dipyridamole $(1 \mathrm{mg} / \mathrm{Kg})$ and phentolamine $(500 \mu \mathrm{g} / \mathrm{Kg})$ augmented both ST elevation and cyclical reductions of flow (group 3). The results indicate that ST elevation due to cyclical reductions of coronary blood flow was eliminated by spasmolytic actions of group 1 on coronary artery, was suppressed by negative chronotropic and/ or inotropic actions of group 2 , and was augmented by peripheral actions of group 3.
\end{abstract}

\section{Additioanl Iadexiag Words :}

Coronary blood flow Surface electrogram Systolic bulge Coronary spasm Prostaglandins

TN 1973, Uchida et al observed cyclical reductions of blood flow in the partially constricted coronary artery of anesthetized dogs, and they suggested participation of coronary spasm induced by prostaglandin $\mathrm{E}_{2}$ in this phenomenon. ${ }^{1)-6)}$ This phenomenon was frequently associated with cyclical elevation of ST segment of surface electrogram and also with ventricular premature contractions, ${ }^{2), 7)}$ and therefore closely resembles Prinzmetal's variant angina pectoris. ${ }^{8)-10)}$ This similarity led us to examine whether the agents which could alleviate attacks in patients with Prinzmetal's variant angina, could also eliminate cyclical reductions of coronary flow and ST elevation of anesthetized dogs.

From the Second Department of Internal Medicine, Faculty of Medicine, University of Tokyo, Hongo, Bunkyo-ku, Tokyo 113, Japan.

This work was partly reported at the 50th session of American Heart Association, Miami Beach, 1977; supported in part by Grant in Aid for Scientific Research, the Ministry of Education, Japanese Government.

Received for publication April 27, 1978. 


\section{METHODS}

\section{Surgical preparations:}

Thirty-five beagle dogs were anesthetized with intravenous sodium pentobarbital $(40-45 \mathrm{mg} / \mathrm{Kg})$. The trachea was intubated for artificial positive pressure respiration with air. The upper 7 ribs on the left side were removed. After pericardiotomy, the proximal segment of either the anterior descending or circumflex artery was dissected free of surrounding tissues and a magnetic flowmeter was placed on it for measurement of coronary blood flow. A segment of the artery 0.5 to $1 \mathrm{~cm}$ distal to the flowmeter was also dissected free and a cylindrical constrictor was placed on it for partial constriction. A small catheter was introduced in retrograde fashion into a small peripheral branch of the artery to measure coronary blood pressurc. A unipolar electrode was fixcd to a portion of the left ventricular wall irrigated by the artery for recording surface electrogram. A force-displacement strain gauge arch was sewn to the ventricular wall to measure contractile force of the myocardium. Another catheter was introduced into the right femoral artery to measure systemic blood pressure. Heart rate was obtained by a pulse-integrator triggered by femoral arterial pressure pulse.

\section{Administrations of chemical agents:}

Cyclical reductions of coronary pressure and flow developed in 30 preparations. In general, coronary pressure and flow decreased gradually and increased rapidly, and the changes were repeated. After recording successive 3 cycles of reduction of coronary pressure and flow, the following agents were injected intravenously $30 \mathrm{sec}$ to $1 \mathrm{~min}$ after the fourth abrupt increase in coronary pressure and flow: nitroglycerin, SG 75(2-nicotinamidoethyl nitrate), ${ }^{11)}$ papaverine, nicotinic acid, nifedipine, verapamil, diltiazem, dipyridamole, propranolol, phentolamine, and atropine. The doses injected were shown in Figs. 6-8. The time from the injection to reappearance of reduction of coronary pressure was compared with the average length of the preceding 3 cycles. It was considered that the agent eliminated the cyclical reductions when the former was significantly longer than the latter. Also, the time from the injection to reappearance of ST elevation of the same magnitude as that before the injection was compared with the average length of the preceding 3 cycles of ST elevation.

\section{Results}

The intravenous injection of $150 \mu \mathrm{g} / \mathrm{Kg}$ of SG 75 caused a slight fall in systemic pressure but no obvious change in heart rate. Following the injection of this dose, cyclical reductions in coronary pressure and flow and ST elevation disappeared. Passive stretching of the myocardium, i.e. the systolic bulge, which was observed in 3 of 5 preparations, also disappeared (Figs. 1 and 6). Twenty-eight to $42 \mathrm{~min}$ after the injection, however, a reduction in coronary pressure reappeared. This reduction was usually small and was not reflected on coronary flow and electrogram (Fig. 1). After 2 to 3 cycles, re- 


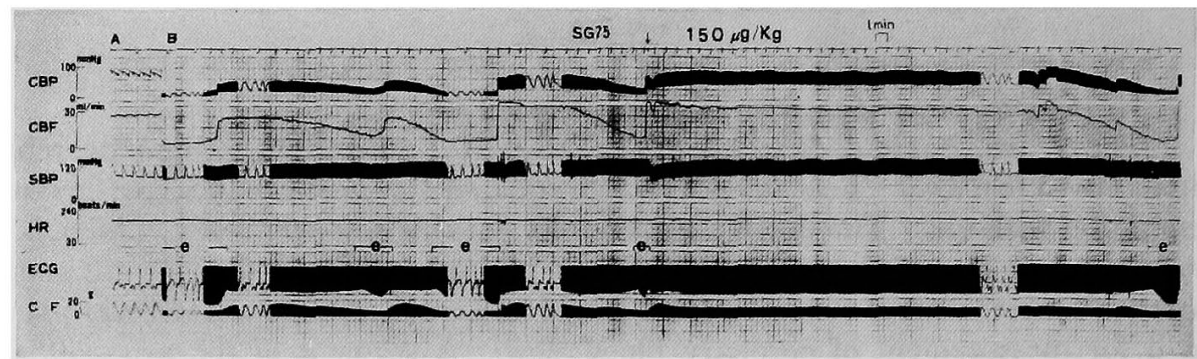

Fig. 1. The effect of intravenous injection of SG 75 on cyclical reductions of coronary flow and ST elevation. From top: coronary pressure (CBP), coronary flow (CBF), systemic pressure (SBP), heart rate (HR), surface electrogram (EGG), and left ventricular contractile force (CF). A: before coronary constriction. B: during coronary constriction. e: ST elevation.

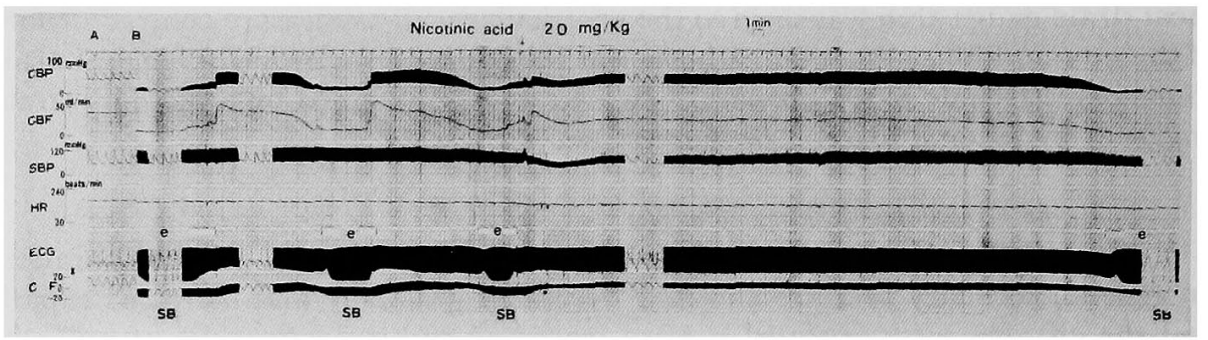

Fig. 2. The effect of nicotinic acid on cyclical reductions of coronary flow and ST elevation. SB: systolic bulge.

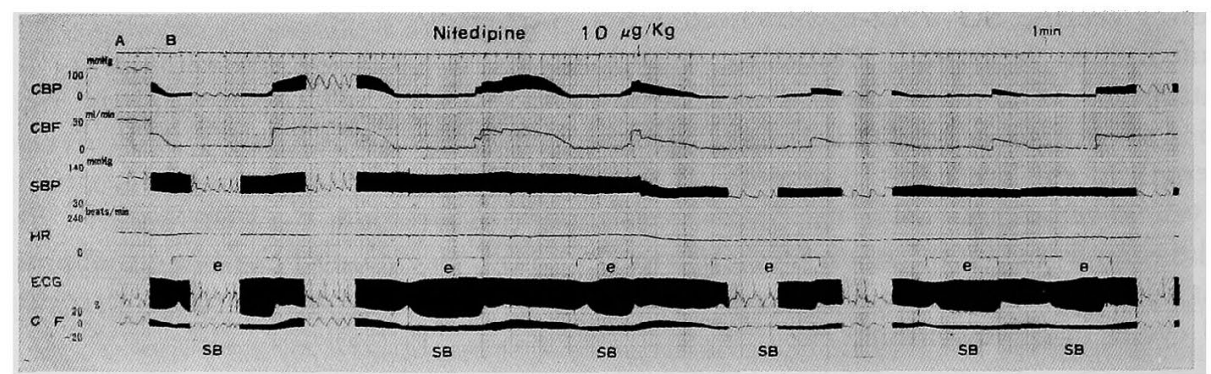

Fig. 3. The effect of nifedipine on cyclical reductions of coronary flow and ST elevation.

duction in pressure became larger and was now associated with ST elevation and reduced contractile force or systolic bulge (Fig. 1). Such a time course was the usual. Accordingly, the time required for reappearance of cyclical reduction in coronary pressure was shorter than that for reappearance of ST elevation (Fig. 6). With increasing dose to $300 \mu \mathrm{g} / \mathrm{Kg}$, the time required for reappearance of cyclical reductions in coronary pressure and ST elevation became longer (Fig. 6 ).

The injections of 50 and $100 \mu \mathrm{g} / \mathrm{Kg}$ of nitroglycerin caused a fall in 


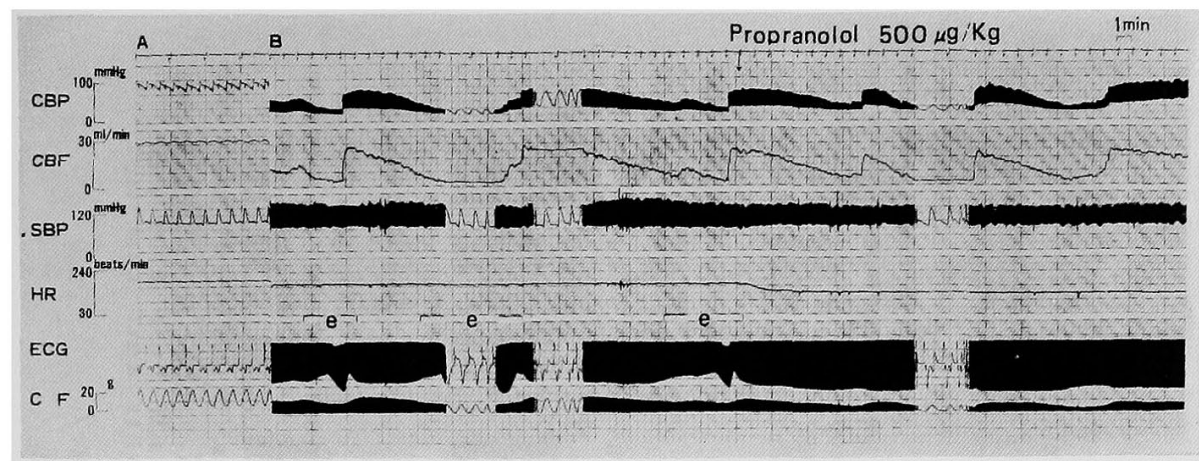

Fig. 4. The effect of propranolol on cyclical reductions of coronary flow and ST elevation.

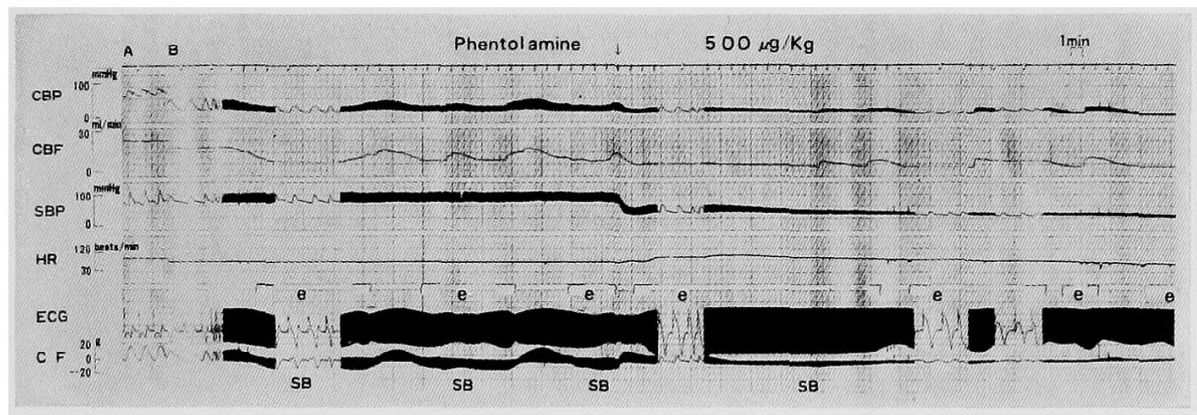

Fig. 5. The effect of phentolamine on cyclical reductions of coronary flow and ST elevation.

systemic pressure and an increase in heart rate. Following the injection of this agent, cyclical reduction in coronary pressure and flow, ST elevation and systolic bulge disappeared as in the case of SG 75 injection (Fig. 6). Cyclical reduction in coronary pressure and flow, ST elevation and systolic bulge were also eliminated by $1 \mathrm{mg} / \mathrm{Kg}$ or over of papaverine and $10 \mathrm{mg} / \mathrm{Kg}$ or over of nicotinic acid (Figs. 2 and 7).

Dipyridamole caused a fall in systemic pressure and an increase in heart rate. However, this agent could not eliminate cyclical reductions in coronary pressure and flow. Although systolic bulge was reduced or eliminated, the magnitude of reduction in coronary flow was increased and ST elevation was augmented by the injection of $1 \mathrm{mg} / \mathrm{Kg}$ of this agent (Fig. 6).

The injections of nifedipine in doses of 5 and $10 \mu \mathrm{g} / \mathrm{Kg}$, diltiazem in doses of $500 \mu \mathrm{g}$ and $1 \mathrm{mg} / \mathrm{Kg}$, and verapamil in a dose of $500 \mu \mathrm{g} / \mathrm{Kg}$ caused a fall in systemic pressure and a decrease in heart rate. Following the injections of these agents, ST elevation and systolic bulge were reduced in magnitude or eliminated. However, reductions in coronary pressure and 

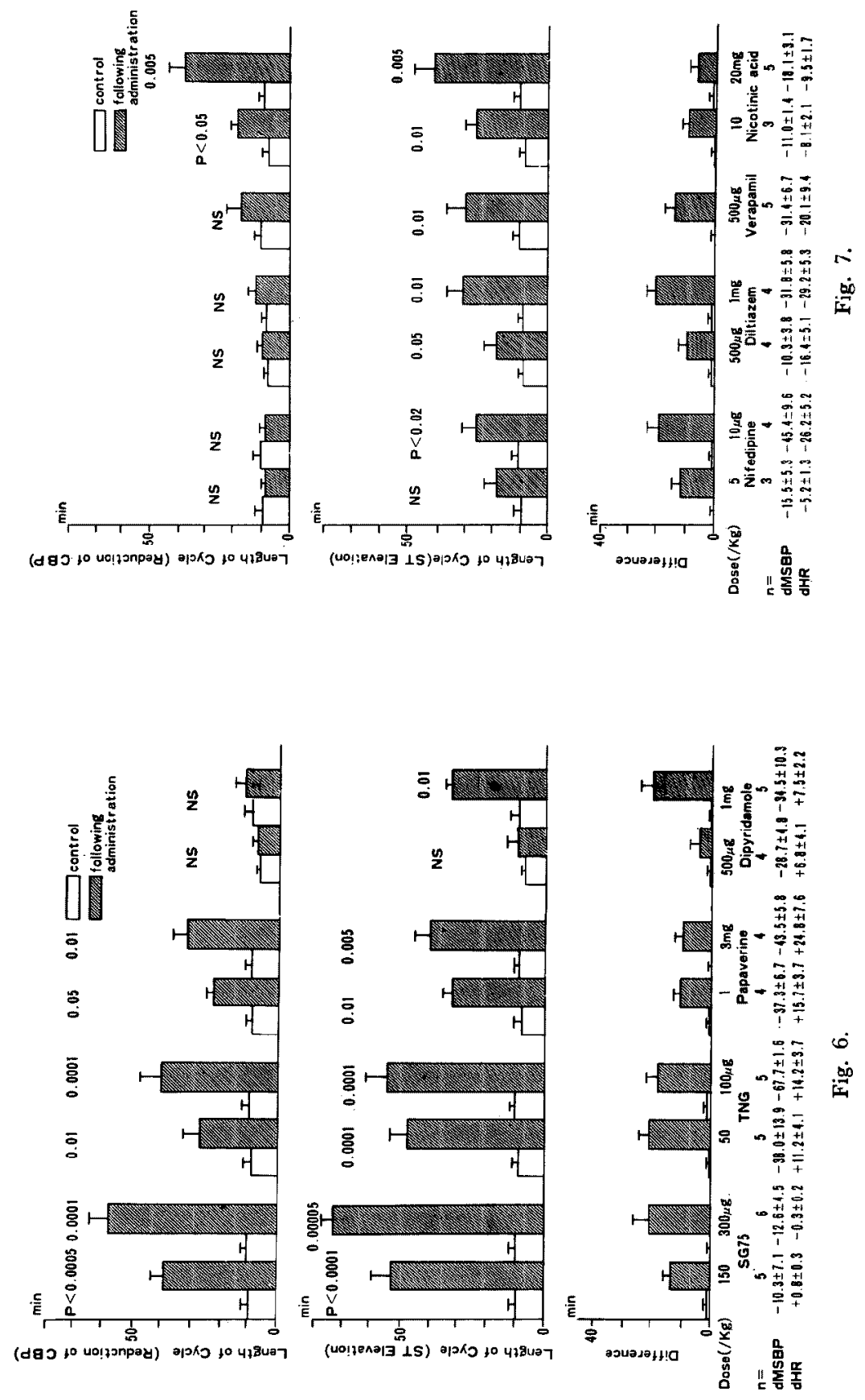

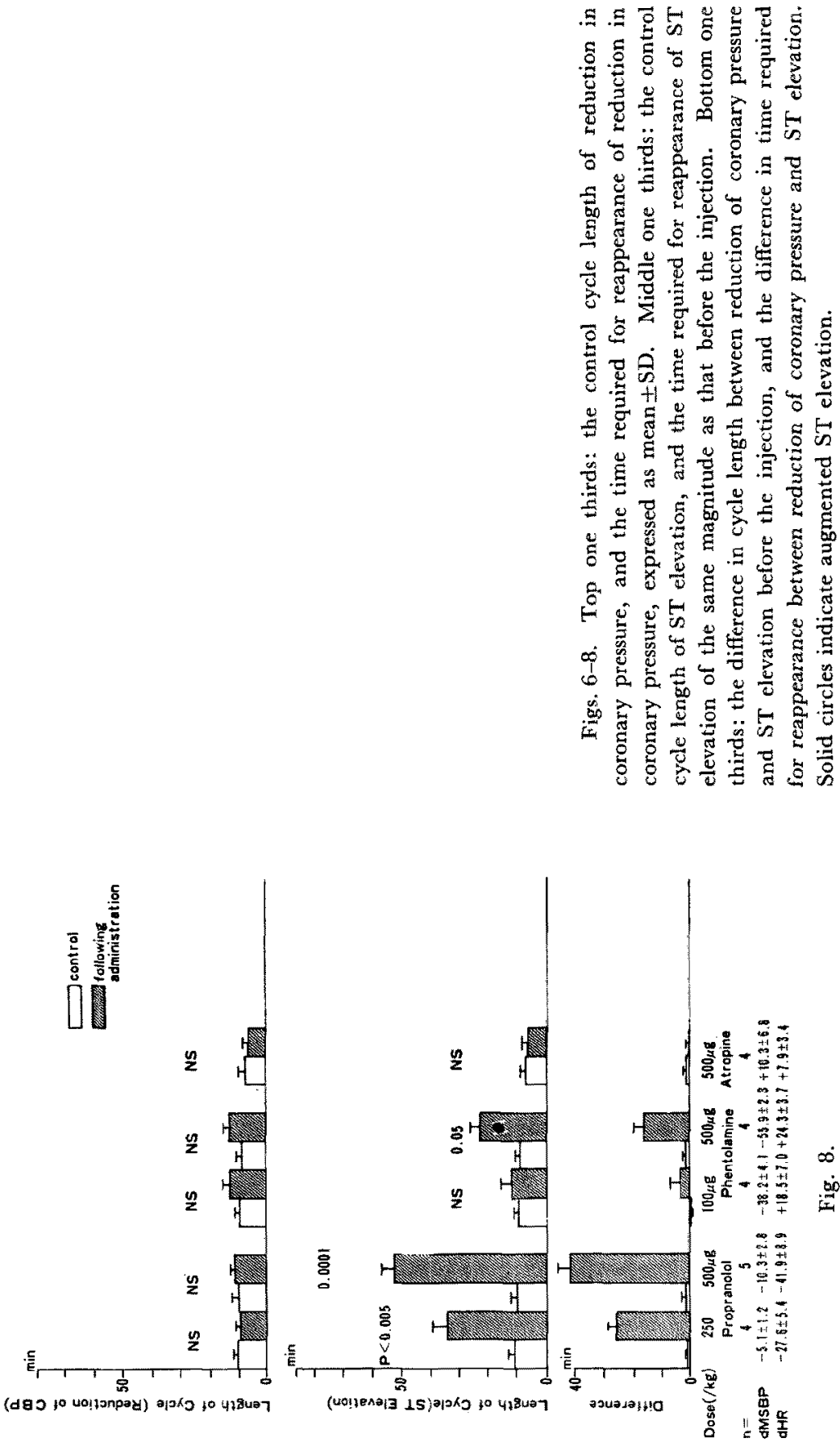
flow were not eliminated and the magnitude of reduction in coronary flow was unchanged or increased (Figs. 3 and 7).

Propranolol caused a slight fall in systemic pressure and a marked decrease in heart rate. Although ST elevation and systolic bulge were suppressed or eliminated, cyclical reductions in coronary pressure and flow were not eliminated as in the case of nifedipine (Figs. 4, 8). Phentolamine caused a fall in systemic pressure and an increase in heart rate as in the case of nitroglycerin and papaverine. Although systolic bulge was suppressed, cyclical reductions in coronary pressure and flow were not eliminated and ST elevation was augmented by $500 \mu \mathrm{g} / \mathrm{Kg}$ of this agent. The changes caused by this agent was similar to those caused by dipyridamole (Figs. 5 and 8). Atropine in a dose of $500 \mu \mathrm{g} / \mathrm{Kg}$ could not affect cyclical reductions in coronary pressure and flow, ST elevation and systolic bulge (Fig. 8).

\section{Discussion}

The underlying mechanisms of the cyclical reductions of blood pressure and flow in the partially constricted coronary artery of anesthetized dogs have been extensively investigated by us. During reductions of coronary pressure and flow, segmental or diffuse narrowing was frequently observed arteriographically in the constricted arteries. ${ }^{3)}$ On the other hand, platelet aggregates were nonspecifically observed in the removed constricted segments of the arteries. ${ }^{3)}$ Therefore, the cyclical reductions in coronary blood pressure and flow were attributed to cyclical spasm of the constricted arteries. The cyclical reductions in coronary blood pressure and flow were eliminated by intravenous injections of aspirin which inhibited synthesis of endoperoxides, ${ }^{13)}$ benzydamine which inhibitted synthesis of endoperoxides and thromboxane (TX) $\mathrm{A}_{2}$, phenylbutazone which inhibited synthesis of endoperoxides and prostaglandin (PG) $\left.\mathrm{F}_{2 \alpha},{ }^{12}\right) \mathrm{Cu}$-chlorophylline which inhibited synthesis of PG $\mathrm{E}_{2}$ and accelerated synthesis of $\mathrm{TXA}_{2}$, and by PG $\mathrm{I}_{2}$ (our unpublished observation), but were not eliminated by imidazoleand 1-methyl-imidasole which selectively inhibited synthesis of TXA $_{\mathbf{2}} \cdot{ }^{14}$ ) The cyclical reductions were frequently induced by epinephrine which accelerated synthesis of $P G E_{2}, P G$ $E_{2}$ itself, and by reduced glutathione which accelerated synthesis of PG $E_{2}$ and inhibited synthesis of $\mathrm{TXA}_{2}$, but were not induced by PG $\mathrm{F}_{2 \alpha}{ }^{5}{ }^{5}$ In addition, the action of $\mathrm{TXA}_{2}$ itself was inconsistent. ${ }^{5)}$ The cyclical reductions were frequently augmented but were not induced by 15-hydroperoxy arachidonic acid which inhibited synthesis of PG $\mathrm{I}_{2}{ }^{15), 16}$ ) Therefore, we considered that $\mathrm{PG} \mathrm{E}_{2}$ but not $\mathrm{TXA}_{2}$ played an important role in coronary spasm and accordingly in cyclical reductions of coronary blood pressure and flow. 
Nitroglycerin, SG 75, papaverine, and nicotinic acid have coronary dilating actions. Among these agents, nitroglycerin and SG 75 climinated coronary spasm in man. ${ }^{10), 17}$ In this study, all these 4 agents eliminated cyclical reductions in coronary pressure and flow, and ST elevation. It is likely that these agents eliminated coronary spasm, leading to elimination of reductions in coronary pressure and flow, and accordingly to elimination of ST elevation. Nitroglycerin has an action to accelerate synthesis of PG $\mathrm{E}_{2}{ }^{18)}$ However, we considered that this agent eliminated cyclical reductions not by its action on PG $\mathrm{E}_{2}$ generating system but by its spasmolytic action on coronary smooth muscles. Although the actions on PG generating systems are not well known, SG 75, papaverine, and nicotinic acid may have eliminated cyclical reductions by their spasmolytic actions on coronary smooth muscles as in the case of nitroglycerin.

Nifedipine, verapamil, diltiazem, and dipyridamole also have coronary dilating actions. In this study, all these agents could not eliminate cyclical rcductions in coronary pressure and flow. Sites of action on coronary artery differ among them. Diltiazem dilated large coronary arteries as in the case of nitroglycerin and SG 75 while the other agents could not. ${ }^{19)}$ It may be considered that nifedipine, verapamil, and dipyridamole could not eliminate spasm which usually occurred in large coronary arteries, and that the dilating action of diltiazem was not enough to eliminate spasm. Although cyclical reductions were not eliminated, ST elevation was suppressed or eliminated by nifedipine, verapamil, and diltiazem. These agents may have suppressed ST elevation by their negative chronotropic and inotropic actions. Similarly, propranolol suppressed ST elevation but it could not eliminate cyclical reductions. It is also likely that this agent suppressed ST elevation by its negative chronotropic and inotropic actions. Differing to these agents, a large dose of dipyridamole augmented ST elevation. A further decrease in coronary flow secondary to a fall in systemic blood pressure and an increase in heart rate may have augmented ST elevation. Also, phentolamine may have augmented ST elevation by the same mechanisms. Despite augmented ST elevation, systolic bulge was suppressed by dipyridamole and phentolamine. Reduced contractile force of the non-ischemic myocardium due to a decrease in after-load and accordingly a decrease in stretching of the ischemic myocardium by the non-ischemic myocardium may have contributed to suppression of systolic bulge.

\section{REFERENCES}

1. Uchida Y, Murao S: Cyclic changes in peripheral blood pressure of partially constricted coronary artery. Jap Coll Angiol 14: 383, 1974 
2. Uchida $Y$, Yoshimoto N, Murao S: Cyclic fluctuations in coronary blood pressure and flow induced by partial constriction of coronary artery. Jap Heart J 16: 454, 1975

3. Uchida Y, Inoue K, Yoshimoto N, Murao S: Cyclical reduction in blood flow of partially constricted coronary artery. II. An arteriographic study. Jap Girculat J 41 : 1221, 1977

4. Uchida Y, Yoshimoto N, Murao S: Effects of aspirin and indomethacin on cyclical reduction in coronary blood flow. Jap Circulat J 41: 101, 1977

5. Uchida $Y$, Yoshimoto N, Murao S: Prostaglandin $E_{2}$ and epinephrine participate in cyclical reduction of coronary blood flow. Jap Heart J 19: 281, 1978

6. Uchida Y: Gyclical reduction of coronary flow. Circulation 56: 332, 1977

7. Uchida $\mathrm{X}$, Yoshimoto N, Murao S: Electrographic changes associated with cyclical reduction of coronary blood flow. Jap Heart J 19 : 493, 1978

8. Murao S, Harumi K, Mashima S, Murayama M, Matsuo H, Uchida Y, Yoshimoto N: Clinical and experimental study on the mechanism of variant angina. Jap J Med 14: 45, 1975

9. Rozanski JJ, Kleinfeld MJ: ST segment alternance in Prinzmetal's variant angina and associated ventricular arrhythmias. Circulation 54 (suppl II): 303, 1976

10. Shubrooks SJ Jr, Bete JM: Variant angina pectoris: clinical and anatomic spectorum and results of coronary artcry bypass surgery. Am J Cardiol 36: 142, 1975

11. Uchida Y, Yoshimoto N, Murao S: Effect of 2-nicotinamidoethyl nitrate (SG 75) on coronary circulation. Jap Heart J 19: 112, 1978

12. Flower RJ, Vane JR: Some pharmacologic and biochemical aspects of prostagiandin biosynthesis and its inhibition. in Prostaglandin Synthetase Inhibitors, ed by Robinson HJ, Vane JR, Raven Press, New York p9, 1974

13. Moncada S, Needleman P, Bunting S, Vane JR: Prostaglandin endoperoxides and thromboxane generating systems and their selective inhibition. Prostaglandins 12: 323, 1976

14. Moncada S, Bunting S, Mullane K, Thorogood P, Vane JR: Imidazole: a selective inhibitor of thromboxane synthetase. Prostaglandins 13: 611, 1977

15. Moncada S, Gryglevski RJ, Bunting S, Vane JR: A lipid peroxides inhibits the enzyme in blood vessel microsomes that generates from prostaglandin endoperoxides the substance (prostaglandin X) which prevents platelet aggregation. Prostaglandins 12: 715, 1976

16. Dusting GJ, Moncada S, Vane JR: Prostacycline is the endogenous metabolites responsible for relaxation of coronary arteries induced by arachidonic acid. Prostaglandins 13: 3, 1977

17. Wada $T$, Endo $M$ : Coronary arteriographic studies on anti-anginal agents. Chiryo 60: 69, 1978 (in Japanese)

18. Morcillo E, Reid P, Dubin N, Ghodgaonkar R, Pitt B: Myocardial prostaglandin E production by nitroglycerm and its modification by indomethacin. Circulation 55, 56 (suppl III): 122,1977

19. Imai S: Anti-anginal actions of coronary vasodilators. Yakkyoku 56: 28, 1976 (in Japanese) 